\title{
A Representation of GM-Variation in Waves by the Volterra System
}

Jianbo Hua

Department of Vehicle Engineering, Royal Institute of Technology, Sweden

Wei-Hui Wang

Professor, Department of System Engineering and Naval Architecture, National Taiwan Ocean University.

Jiang-Ren Chang

Associate Professor, Department of System Engineering and Naval Architecture, National Taiwan Ocean Unviersity

Follow this and additional works at: https://jmstt.ntou.edu.tw/journal

Part of the Engineering Commons

\section{Recommended Citation}

Hua, Jianbo; Wang, Wei-Hui; and Chang, Jiang-Ren (2009) "A Representation of GM-Variation in Waves by the Volterra System," Journal of Marine Science and Technology. Vol. 7: Iss. 2, Article 4.

DOI: $10.51400 / 2709-6998.2527$

Available at: https://jmstt.ntou.edu.tw/journal/vol7/iss2/4

This Research Article is brought to you for free and open access by Journal of Marine Science and Technology. It has been accepted for inclusion in Journal of Marine Science and Technology by an authorized editor of Journal of Marine Science and Technology. 


\title{
A REPRESENTATION OF GM-VARIATION IN WAVES BY THE VOLTERRA SYSTEM
}

\author{
Jianbo Hua*, Wei-Hui Wang** and Jiang-Ren Chang***
}

Keywords: GM-variation, RoRo-ship, Transfer function, Volterra System.

\begin{abstract}
As known, the variation of the metacentric height of a ship in irregular waves is not a pure linear process, particular when a ship has large beam to draught ratio and large flare near the waterline at bow and stern. This kind of unconventional hull form is usually adopted for modern RoRo-ship, cruise-ship etc. which allows large cargo space and high service speed. In this paper, the GM-variation is derived into a function series with respect to the variation order and represented by the Volterra system. The transfer functions for the different orders are integrated numerically or analytically through expressing the sectional beam, area and moment in Taylor's series as function of the momentary water line. Thereby the explicit relationship between the hull form and GM-variation can be obtained. The numerical result has shown the significant effect of the second order term in the Volterra system on the GM-variation in waves. Hence, the non-linear characteristics of the GM-variation in an irregular wave can be easily analyzed by means of available nonlinear probability theories or Monte-Carlo simulation technique.
\end{abstract}

\section{INTRODUCTION}

In her service life, a ship will involuntarily experience a lot occasions of storm weather and rough seas, during which some dynamic problems can happen to the ship. For example, roll motion in resonance with the wave excitation, roll motion due to stability reduction or loss in combination with wind- or wave-induced excitation moment, and parametrically excited roll motion. The GM-variation of a ship in wave is an important evaluation factor in the latter two problems, and that is why it has been an interesting object for research internationally during the past years [1-3].

It has been always desired to explain the basic mechanisms behind different ship dynamic stability

Paper Received June 28, 1999. Revised September 15, 1999. Accepted October 25, 1999. Author for Correspondence: Jianbo Hua.

*Department of Vehicle Engineering, Royal Institute of Technology, Sweden

**Professor, Department of System Engineering and Naval Architecture, National Taiwan Ocean University.

***Associate Professor, Department of System Engineering and Naval Architecture, National Taiwan Ocean Unviersity. problems by means of some basic parameters, which can not only provide explicit description of relationship between the ship main particulars and its dynamic behavior, but also result in design criteria for dynamic stability. However, owing to the limited computation capacity before 1970's, the analyses for the effect of GM-variation on the dynamic stability problems were mostly qualified by assuming linear relationship on the wave amplitude, see [1] by Dunwoody. He derived an explicit formulation for the GM-variation related to the hull form as a linear response to the wave elevation along a ship, therefore, the spectrum theory could be applied for description of the GM-variation of a ship in long crested seas. It provides the possibility for study of ship roll behavior by means of an idealized single differential equation. When calculating the heave and pitch motions of the quasi-static equilibrium is assumed, i.e., only the Froude-Kryloff forces are taken into account.

Nevertheless, the GM-variation has nonlinear characteristics in relation to the wave amplitude and the degree of nonlinearity is dependent on the hull form. The numerical investigation into the GM-variation in regular and irregular waves by Palmquist [4] in 1994 has shown that the GM-variation in an irregular wave can be described by a sum of a linear Gaussian process and a nonlinear process due to the higher order influence. Besides, the numerical result has also shown that the nonlinear process is strongly coupled with the evolution of the linear Gaussian process.

In this paper, the GM-variation has been derived into a series with respect to the variation order and then represented by the Volterra system. The transfer functions for the different orders are integrated analytically by means of expressing the sectional beam and moment into Taylor's series as a function of the momentary draft change around the mean one. As similar as a function, $f(x)$, can be expressed in a Taylor's series:

$$
\begin{aligned}
f(h+x) & =f(h)+f^{\prime}(h) \cdot x+\frac{1}{2 !} \cdot f^{\prime \prime}(h) \cdot x^{2}+\cdots \\
& +\frac{1}{(n+1) !} \cdot f^{n-1}(h) \cdot x^{n-1}+R_{n} .
\end{aligned}
$$


a nonlinear system can be written in the form of Volterra system [5],

$$
\begin{aligned}
y(t) & =\sum_{n=1}^{\infty} \int_{-\infty}^{\infty} \cdots \int_{-\infty}^{\infty} h_{n}\left(\sigma_{1}, \cdots, \sigma_{n}\right) \\
& \cdot u\left(t-\sigma_{1}\right) \cdots u\left(t-\sigma_{n}\right) \cdot d \sigma_{1} \cdots d \sigma_{n},
\end{aligned}
$$

where $u(t)$ is the input signal and also the wave elevation in our case, and $h_{n}\left(\sigma_{1}, \ldots, \sigma_{n}\right)$ are kernel functions for the nonlinear system. When the input signal $u(t)$ is a stochastic variable represented by a power spectrum, the system can be rewritten in the following way

$$
y(t)=\sum_{n=1}^{N} H_{1}\left(\omega_{n}\right) \cdot e^{i \omega_{n} t+\beta_{n}}
$$

for a linear system, and

$$
y(t)=\sum_{m=1}^{M} \sum_{n=1}^{N} H_{2}\left(\omega_{m} \pm \omega_{n}\right) \cdot e^{i\left(\omega_{m} \pm \omega_{n}\right) t+\beta_{m n}}
$$

for a second order system, and so on. Where $\omega_{m}$ and $\omega_{n}$ in the above Eqs. denote frequency. $\beta_{m n}$ and $\beta_{n}$ are phase angles. $i=\sqrt{-1}$. The transfer functions, $H_{1}(\omega)$ and $H_{1}\left(\omega_{1}, \omega_{2}\right)$, are the Fourier's transforms of $h_{1}(\sigma)$ and $h_{2}\left(\sigma_{1}, \sigma_{2}\right)$ in Eq. (2). Our task in the following is to derive the transfer functions $H_{1}(\sigma)$ and $H_{2}\left(\sigma_{1}, \sigma_{2}\right)$ to represent the GM-variation of a ship in waves. If needed, $h_{1}(\sigma)$ and $h_{2}\left(\sigma_{1}, \sigma_{2}\right)$ can be obtained by inverse Fourier's transforms of $H_{1}(\sigma)$ and $H_{2}\left(\sigma_{1}, \sigma_{2}\right)$.

\section{GM-VARIATION AS AN INTEGRATION SERIES}

Mathematically, the section beam of a ship as a function of draft can be expanded around the mean draft $T(x)$ as a Taylor's series

$$
\begin{aligned}
B(x, T(x)+z) & =B(x, T(x))+\frac{\partial B}{\partial z} \cdot z+\frac{1}{2 !} \frac{\partial^{2} B}{\partial z^{2}} \cdot z^{2} \\
& +\frac{1}{3 !} \frac{\partial^{3} B}{\partial z^{3}} \cdot z^{3}+\cdots,
\end{aligned}
$$

where $z$ is a variable for the sectional draft change. As well for the sectional moment with respect to the keel line,

$$
\begin{aligned}
M(x, T(x)+z & =M(x, T(x))+\frac{\partial M}{\partial z} \cdot z+\frac{1}{2 !} \frac{\partial^{2} M}{\partial z^{2}} \cdot z^{2} \\
& +\frac{1}{3 !} \frac{\partial^{3} M}{\partial z} \cdot z^{3}+\cdots,
\end{aligned}
$$

and the sectional area,

$$
\begin{aligned}
A(x, T(x)+z) & =A(x, T(x))+\frac{\partial A}{\partial z} \cdot z+\frac{1}{2 !} \frac{\partial^{2} A}{\partial z^{2}} \cdot z^{2} \\
& +\frac{1}{3 !} \frac{\partial^{3} A}{\partial z^{3}} \cdot z^{3}+\cdots
\end{aligned}
$$

For the sake of simplicity, Eqs. (5) to (7) can be respectively expressed as

$$
\begin{aligned}
B(x, T(x)+z) & =B(x, T(x))+c_{1}(x) \cdot z+c_{2}(x) \cdot z^{2} \\
& +c_{3}(x) \cdot z^{3}+\ldots ; \\
M(x, T(x)+z) & =M(x, T(x))+d_{1}(x) \cdot z+d_{2}(x) \cdot z^{2} \\
& +d_{3}(x) \cdot z^{3}+\ldots ; \\
A(x, T(x)+z) & =A(x, T(x))+e_{1}(x) \cdot z+e_{2}(x) \cdot z^{2} \\
& +e_{3}(x) \cdot z^{3}+\ldots ;
\end{aligned}
$$

where

$$
\begin{array}{lll}
c_{1}(x)=\frac{\partial B}{\partial z}, & c_{2}(x)=\frac{1}{2 !} \frac{\partial^{2} B}{\partial z^{2}}, & c_{3}(x)=\frac{1}{3 !} \frac{\partial^{3} B}{\partial z^{3}}, \cdots \\
d_{1}(x)=\frac{\partial M}{\partial z}, & d_{2}(x)=\frac{1}{2 !} \frac{\partial^{2} M}{\partial z^{2}}, & d_{3}(x)=\frac{1}{3 !} \frac{\partial^{3} M}{\partial z^{3}}, \cdots ; \\
e_{1}(x)=\frac{\partial A}{\partial z}, & e_{2}(x)=\frac{1}{2 !} \frac{\partial^{2} A}{\partial z^{2}}, & e_{3}(x)=\frac{1}{3 !} \frac{\partial^{3} A}{\partial z^{3}}, \cdots
\end{array}
$$

It should be noted that $c_{i}(x), d_{i}(x), e_{i}(x)$ can be obtained numerically by using the piecewisely polynomial functions fitting the section beam, section moment and section area along the ship.

The initial metacentric height $G M_{0}$ at the mean draft in still water can be calculated as followed:

$$
G M_{0}=K B+B M-K G,
$$

where $K B$ is the height of buoyancy center $B$ above the keel $K$ and defined as

$$
K B=\frac{1}{\nabla} \int_{L} M(x, T(x)) d x,
$$

$B M$ is the height of transverse metacenter $M$ above buoyancy center $B$ and defined as

$$
B M=\frac{1}{12 \cdot \nabla} \int_{L} B^{3}(x, T(x)) d x,
$$

and $K G$ is the height of mass center $G$ above the keel $K$. In the above two equations, $\nabla$ and $L$ denote displacement volume and length of the target ship respectively. The initial GM-variation of a ship in a longitudinal regular or irregular wave then becomes by neglecting the Smith-effect

$$
\begin{aligned}
\partial G M & =\frac{1}{\nabla} \int_{L}\left[\frac{B^{3}(x, T(x)+r(x))}{12}+M(x, T(x)+r(x))\right. \\
& -A(x, T(x)+r(x)) K G(x)] d x-G M_{0}
\end{aligned}
$$

where the sectional mass center above the keel,

$$
K G(x)=K G+x \cdot\left(\eta_{5}-\alpha_{\text {trim }}\right) .
$$


Table 1. The ship's main particulars

\begin{tabular}{cccccc}
\hline $\mathrm{L}_{\mathrm{pp}}(\mathrm{mm})$ & $\mathrm{B}(\mathrm{m})$ & $\mathrm{T}(\mathrm{m})$ & $\mathrm{C}_{\mathrm{b}}$ & $\mathrm{KG}(\mathrm{m})$ & $\mathrm{GM}_{0}(\mathrm{~m})$ \\
\hline 180 & 27.3 & 9.1 & 0.64 & 11.2 & 0.81 \\
\hline
\end{tabular}

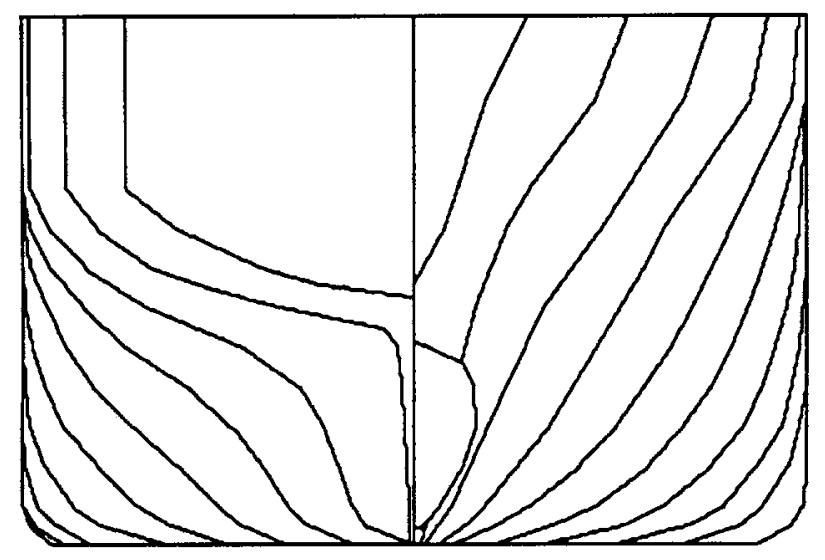

Fig. 1. The hull form.

$\eta_{5}$ in (15) is the wave-induced pitch angle and $\alpha_{\text {trim }}$ the trim angle in still water.

First replacing the variable $z$ in Eqs. (8) to (10) with, the relative motion of the wave surface against ship, and then substituting Eqs. (8) to (10) into Eq. (14), the following expression can be yielded

$$
\partial G M=\sum_{i} \partial G M_{i}
$$

where

$$
\begin{aligned}
\partial G M_{1} & =\frac{1}{\nabla} \int_{L}\left[\frac{B^{2}(x, T) c_{1}(x)}{4}+d_{1}(x)-K G e_{1}(x)\right] r(x) d x \\
\partial G M_{2} & =\frac{1}{\nabla} \int_{L}\left[\frac{3 B^{2}(x, T) c_{2}(x)+3 B(x, T) c_{2}^{2}(x)}{12}+d_{2}(x)\right. \\
& \left.-K G e_{2}(x)\right] r^{2}(x, t) d x-\frac{1}{\nabla} \int_{L} x e_{1}(x) \eta_{5} r(x) d x
\end{aligned}
$$

and so on. Let

$$
\begin{aligned}
G_{1}(x) & =\frac{1}{\nabla}\left[\frac{B^{2}(x, T) c_{1}(x)}{4}+d_{1}(x)-K G e_{1}(x)\right] \\
G_{2}(x) & =\frac{1}{\nabla}\left[\frac{3 B^{2}(x, T) c_{2}(x)+3 B(x, T) c_{1}^{2}(x)}{12}\right. \\
& \left.+d_{2}(x)-K G e_{2}(x)\right] \\
R_{2}(\omega, x) & =\frac{-x e_{1}(x) \eta_{5}}{\nabla}=\frac{-x B(x, T(x)) \eta_{5}}{\nabla} \\
G_{3}(x) & =\frac{1}{\nabla}\left[\frac{3 B^{2}(x, T) c_{3}(x)+6 B(x, T) c_{1}(x) c_{2}(x)+c_{1}^{3}(x)}{12}\right.
\end{aligned}
$$
flares around the warterline areas in the fore and aft bodies. Fig. 3 shows the $G_{1}(x), G_{2}(x)$ and $G_{3}(x)$ along the ship. As seen, $G_{1}(x)$ is the greatest, $G_{2}(x)$ is in one order less than $G_{1}(x)$, and $G_{3}(x)$ one order less than

and so on, such that

$$
\partial G M_{i}=\int_{L} G_{i}(x) r^{i}(x, t) d x+\int_{L} R_{i}(x) r^{i-1}(x, t) d x .
$$

It clearly shows that $G_{i}(x)$ can be considered as the characteristic function describing the hull geometry near the water line with respect to the GM-variation of a ship in waves. $R_{i}(x)(i \geq 2)$ is a function linearly depending upon the pitch response and contributes to the higher order GM-variation.

\section{AN EXAMPLE OF THE GM-VARIATION OF A SHIP IN REGULAR FOLLOWING WAVES}

The target ship in the example is an ordinary RoRo-ship. Similar ships were constructed mostly under seventies. The ship has a aspect ratio of the beam to draught equal to three. Actually, the aspect ratio of modern RoRo-ship or cruise ships are often around four. The main particulars of the ship are shown in Table 1 and the hull form is shown in Fig. 1. In Fig. 2, $G_{1}(x)$ is shown along the ship. For comparison, the contributions from the first, second and third term in Eq. (17) are also demonstrated. Apparently, the contribution from the first term has the dominant portion in $G_{1}(x)$, particular in the aft body. Because large relative motion usually takes place in the fore and aft bodies, the conclusion can be drawn that the first order GM-variation of the ship in following wave is mainly due to the large 


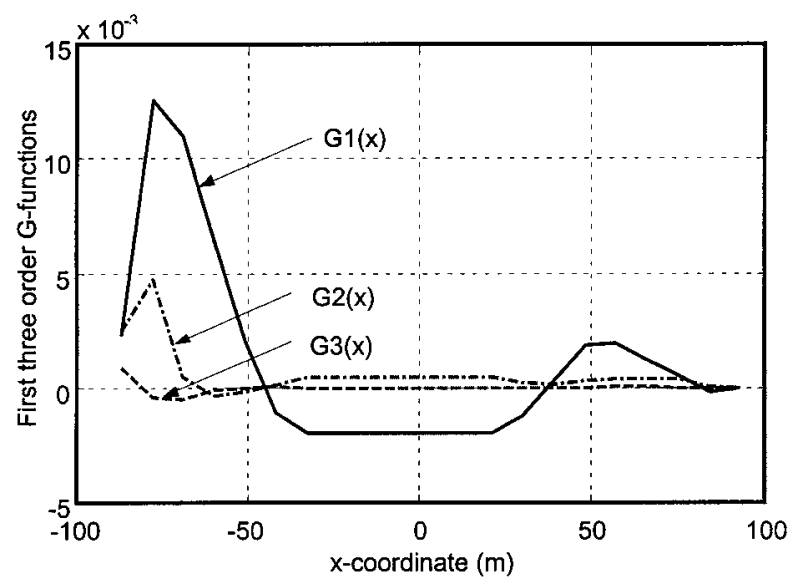

Fig. 3. First three order G-functions.

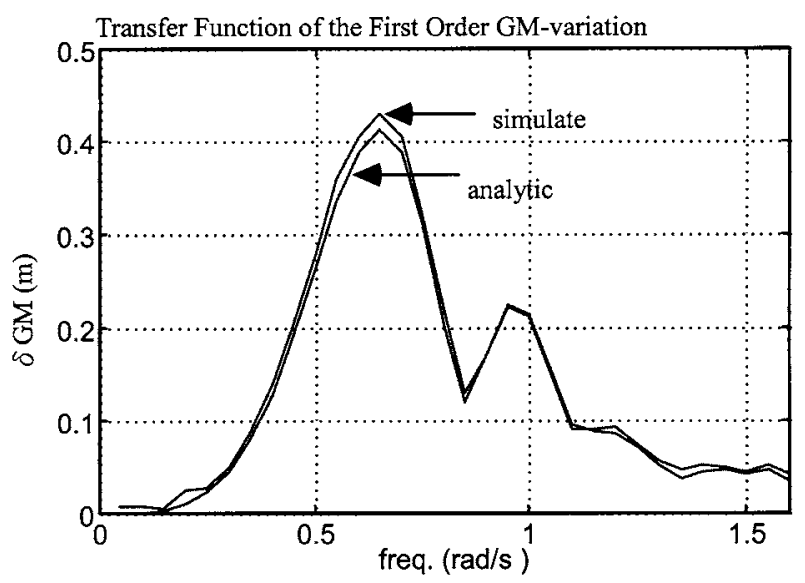

Fig. 4. Comparison of the transfer functions of the first order GM-variation from the simulation and analytical calculation without consideration to the Smith effect.

$G_{2}(x)$.

The first order GM-variation of the ship in following regular waves calculated using the actual method is compared with the one using a simulation method similar to the one used by Palmquist [4] in 1994. The result without consideration to the Smith-effect shows good agreements as shown in Fig. 4. While in Fig. 5, the comparison is shown with consideration to the Smitheffect. It should be noted that in the actual method, the Smith-effect is taken into account only in the calculation of heave and pitch motion in regular waves.

\section{VOLTERRA SYSTEM REPRESENTATION OF GM-VARIATION IN IRREGULAR WAVES}

The elevation equation for a regular wave is

$$
\eta(x, t)=\frac{1}{2} a \cdot\left[e^{i(k x-\omega t+\beta)}+e^{-i(k x-\omega t+\beta)}\right] .
$$

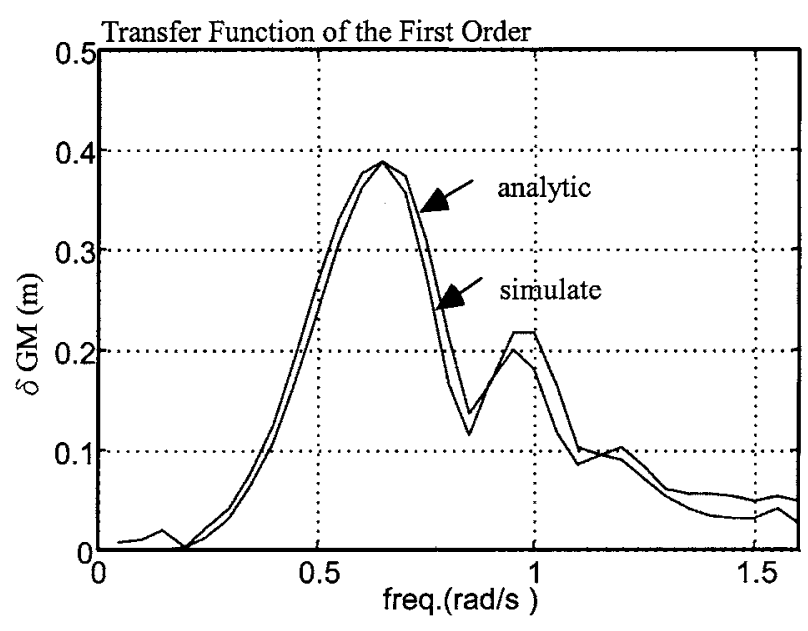

Fig. 5. Comparison of the transfer functions of the first order GM-variation from the simulation and analytical calculation with consideration to the Smith effect.

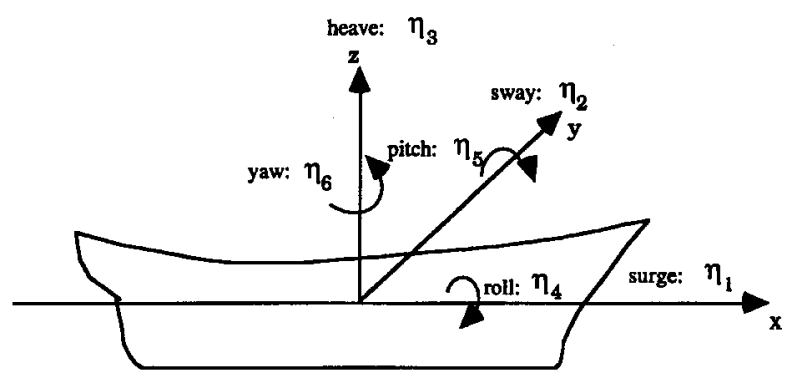

Fig. 6. Ship-fixed co-ordinate system and the definition of the six degrees of motion freedom.

An irregular wave is a wave system consisting of a series harmonic wave components and its elevation is written as followed:

$$
\eta(x, t)=\frac{1}{2} \cdot\left\{\sum_{n=1}^{N} a_{n} \cdot\left[e^{i(k} n^{\left.x-\omega_{n} t+\beta_{n}\right)}+e^{-i\left(k n_{n} x-\omega_{n} t+\beta_{n}\right)}\right]\right\}
$$

$\omega$ and $\omega_{n}$ in the above denote wave frequency. $k=\frac{\omega^{2}}{g}$, and $k_{n}=\frac{\omega_{n}^{2}}{g}$ both denote the wave number. Random wave phase $\beta$ and $\beta_{n}$ follow the uniform distribution between $[\pi-\pi]$.

Assuming that a ship's heave and pitch motion in regular waves follow the linear relation to the wave amplitude, the relative motion, as shown in Fig. 6, of the ship against the irregular wave can then be written as followed,

$$
r(x, t)=\frac{1}{2} \sum_{n=1}^{N} a_{n} \cdot\left[e^{i k} n^{x}-\eta_{3}\left(\omega_{n}\right)+x \cdot \eta_{5}\left(\omega_{n}\right)\right]
$$




$$
\begin{aligned}
& \cdot e^{-i\left(\omega_{n} t+\beta_{n}\right)}+\frac{1}{2} \sum_{n=1}^{N} a_{n} \\
& \cdot\left[e^{-i k} n^{x}-\bar{\eta}_{3}\left(\omega_{n}\right)+x \cdot \bar{\eta}_{5}\left(\omega_{n}\right)\right] \cdot e^{i\left(\omega_{n} t+\beta_{n}\right)}
\end{aligned}
$$

or

$$
\begin{aligned}
r(x, t) & =\sum_{n=1}^{N} a_{n} \cdot\left[v\left(\omega_{n}, x\right) \cdot e^{-i\left(\omega_{n} t+\beta_{n}\right)}\right. \\
& \left.+\bar{v}\left(\omega_{n}, x\right) \cdot e^{i\left(\omega_{n} t+\beta_{n}\right)}\right]
\end{aligned}
$$

where the transfer functions of the relative motion are defined by:

$$
\begin{aligned}
& v\left(\omega_{n}, x\right)=\frac{1}{2}\left[e^{i k_{n} x}-\eta_{3}\left(\omega_{n}\right)+x \cdot \eta_{5}\left(\omega_{n}\right)\right] \\
& \bar{v}\left(\omega_{n}, x\right)=\frac{1}{2}\left[e^{i k_{n} x}-\bar{\eta}_{3}\left(\omega_{n}\right)+x \cdot \bar{\eta}_{5}\left(\omega_{n}\right)\right] .
\end{aligned}
$$

Obviously, the sum of the above two transfer functions is a real number, i.e., $\bar{v}\left(\omega_{n}, x\right)$ is conjunct to $v\left(\omega_{n}, t\right)$. The pitch motion in irregular waves is

$$
\begin{aligned}
\eta_{5}(t) & =\frac{1}{2} \sum_{n=1}^{N} a_{n} \cdot\left[\eta_{5}\left(\omega_{n}\right) \cdot e^{-i\left(\omega_{n} t+\beta_{n}\right)}\right. \\
& \left.+\bar{\eta}_{5}\left(\omega_{n}\right) \cdot e^{i\left(\omega_{n} t+\beta_{n}\right)}\right] .
\end{aligned}
$$

The transfer functions for heave and pitch motions are obtained by the linear ship motion theory and the wave-induced motion is considered, we have

$$
\begin{aligned}
\eta_{5}(t) \cdot r(x, t) & =\sum_{m=1}^{M} \sum_{n=1}^{N} a_{m} a_{n} \cdot\left[\eta_{5}\left(\omega_{m}\right) \cdot v\left(\omega_{n}, x\right) \cdot e^{-i k_{1}}\right. \\
& +\eta_{5}\left(\omega_{m}\right) \cdot \bar{v}\left(\omega_{n}, x\right) \cdot e^{\left.-i k_{2}\right]} \\
& +\sum_{m=1}^{M} \sum_{n=1}^{N} a_{m} a_{n} \cdot\left[\bar{\eta}_{5}\left(\omega_{m}\right) \cdot v\left(\omega_{n}, x\right) \cdot e^{-i k_{3}}\right. \\
& +\bar{\eta}_{5}\left(\omega_{m}\right) \cdot \bar{v}\left(\omega_{n}, x\right) \cdot e^{\left.-i k_{4}\right]}
\end{aligned}
$$

and

$$
\begin{aligned}
r^{2}(x, t) & =\sum_{m=1}^{M} \sum_{n=1}^{N} a_{m} a_{n} \cdot\left[v\left(\omega_{m}\right) \cdot v\left(\omega_{n}, x\right) \cdot e^{-i k_{1}}\right. \\
& \left.+v\left(\omega_{m}\right) \cdot \bar{v}\left(\omega_{n}, x\right) \cdot e^{-i k_{2}}\right] \\
& +\sum_{m=1}^{M} \sum_{n=1}^{N} a_{m} a_{n} \cdot\left[\bar{v}\left(\omega_{m}\right) \cdot v\left(\omega_{n}, x\right) \cdot e^{-i k_{3}}\right. \\
& \left.+\bar{v}\left(\omega_{m}\right) \cdot v\left(\omega_{n}, x\right) \cdot e^{-i k_{4}}\right]
\end{aligned}
$$

where

$$
\begin{aligned}
& k_{1}=\left(\omega_{m}+\omega_{n}\right) t+\beta_{m}+\beta_{n} ; \\
& k_{2}=\left(\omega_{m}-\omega_{n}\right) t+\beta_{m}-\beta ; \\
& k_{3}=k_{2} ;
\end{aligned}
$$

$$
k_{4}=k_{1}
$$

By substituting Eq. (26), (27) and (28) into (17), the transfer function of the first order GM-variation is obtained

$$
\left.\begin{array}{l}
f_{1}(\omega)=\int_{L} G_{1}(x) \cdot v(\omega, x) \cdot d x \\
\bar{f}_{1}(\omega)=\int_{L} G_{1}(x) \cdot \bar{v}(\omega, x) \cdot d x
\end{array}\right\}
$$

such that

$$
\begin{aligned}
\partial G M_{1}(t) & =\sum_{n=1}^{N} a_{n} \cdot\left[f_{1}\left(\omega_{n}\right) \cdot e^{-i\left(\omega_{n} t+\beta_{n}\right)}+\bar{f}_{1}\left(\omega_{n}\right)\right. \\
& \left.\cdot e^{-i\left(\omega_{n} t+\beta_{n}\right)}\right] .
\end{aligned}
$$

The transfer functions of the second order GMvariation become

$$
\left.\begin{array}{l}
u_{2}\left(\omega_{m}, \omega_{n}\right)=\int_{L}\left[G_{2}(x) \cdot v\left(\omega_{m}, x\right) \cdot v\left(\omega_{n}, x\right)+R_{2}\left(\omega_{m}, x\right) \cdot v\left(\omega_{n}, x\right)\right] d x \\
\bar{u}_{2}\left(\omega_{m}, \omega_{n}\right)=\int_{L}\left[G_{2}(x) \cdot v\left(\omega_{m}, x\right) \cdot \bar{v}\left(\omega_{n}, x\right)+R_{2}\left(\omega_{m}, x\right) \cdot \bar{v}\left(\omega_{n}, x\right)\right] d x \\
v_{2}\left(\omega_{m}, \omega_{n}\right)=\int_{L}\left[G_{2}(x) \cdot \bar{v}\left(\omega_{m}, x\right) \cdot v\left(\omega_{n}, x\right)+\bar{R}_{2}\left(\omega_{m}, x\right) \cdot v\left(\omega_{n}, x\right)\right] d x \\
\bar{v}_{2}\left(\omega_{m}, \omega_{n}\right)=\int_{L}\left[G_{2}(x) \cdot \bar{v}\left(\omega_{m}, x\right) \cdot v\left(\omega_{n}, x\right)+\bar{R}_{2}\left(\omega_{m}, x\right) \cdot \bar{v}\left(\omega_{n}, x\right)\right] d x
\end{array}\right\},
$$

Thereby,

$$
\begin{aligned}
\partial G M_{2}(t) & =\sum_{m=1}^{M} \sum_{n=1}^{N} a_{m} a_{n} \cdot\left\{u_{2}\left(\omega_{m}, \omega_{n}\right) \cdot e^{-i\left[\left(\omega_{m}+\omega_{n}\right) t+\beta_{m}+\beta_{n}\right]}\right. \\
& \left.+\bar{u}_{2}\left(\omega_{m}, \omega_{n}\right) \cdot e^{-i\left[\left(\omega_{m}-\omega_{n}\right) t+\beta_{m}-\beta_{n}\right]}\right\} \\
& \sum_{m=1}^{M} \sum_{n=1}^{N} a_{m} a_{n} \cdot\left\{v_{2}\left(\omega_{m}, \omega_{n}\right) \cdot e^{i\left[\left(\omega_{m}-\omega_{n}\right) t+\beta_{m}-\beta_{n}\right]}\right. \\
& \left.+\bar{v}_{2}\left(\omega_{m}, \omega_{n}\right) \cdot e^{i\left[\left(\omega_{m}+\omega_{n}\right) t+\beta_{m}+\beta_{n}\right]}\right\}
\end{aligned}
$$

and so on for the higher order GM-variation.

According to the definition in (34), $\bar{v}\left(\omega_{m}, \omega_{n}\right)$ is conjunct to $u_{2}\left(\omega_{m}, \omega_{n}\right)$ and $v_{2}\left(\omega_{m}, \omega_{n}\right)$ to $\bar{u}_{2}\left(\omega_{m}, \omega_{n}\right)$. Eq. (35) shows that the second order GM-variation consists of two parts, i.e. high frequency variation and $\bar{u}_{2}\left(\omega_{m}, \omega_{n}\right)$ slow varying part. $u_{2}\left(\omega_{m}, \omega_{n}\right)$ represents the transfer functions for high frequency variation and $\bar{u}_{2}\left(\omega_{m}, \omega_{n}\right)$ slow varying. Fig. 7 and Fig. 8 show the real and imaginary part of $u_{2}\left(\omega_{m}, \omega_{n}\right)$ respectively. Fig. 9 and Fig. 10 show the real and imaginary part of $\bar{u}_{2}\left(\omega_{m}, \omega_{n}\right)$ respectively.

Fig. 11 shows an example of the first and second order GM-variation in an irregular wave. As seen in the figure, the second order GM-variation is positive all the time and gives in increase in the GM-variation. The 


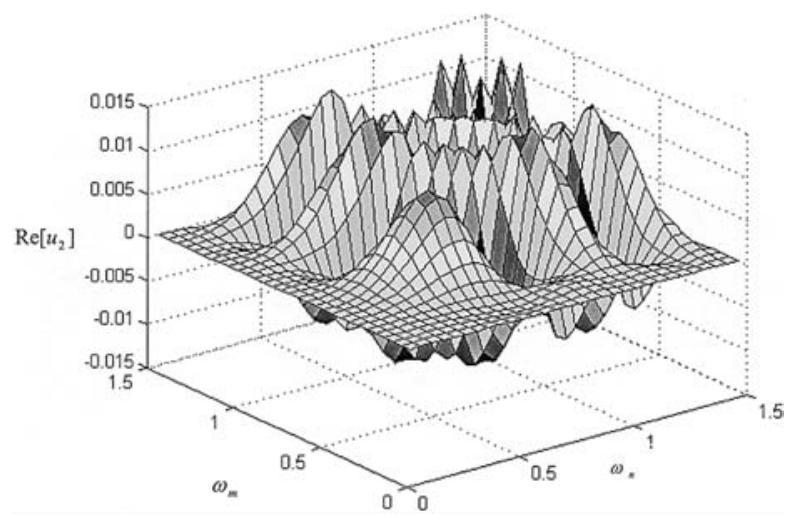

Fig. 7. Real part of $u_{2}\left(\omega_{m}, \omega_{n}\right)$. The unit for $u_{2}$ is $1 / \mathrm{m}$, and rad $/ \mathrm{s}$ for the wave frequency.

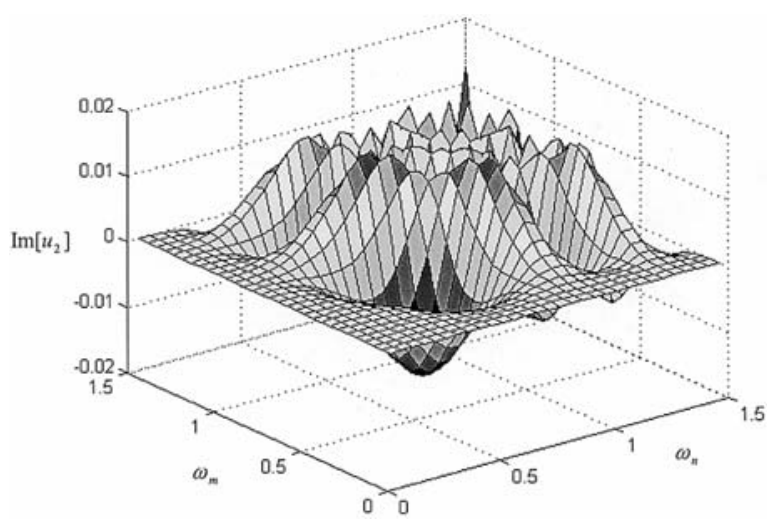

Fig. 8. Imaginary part of $u_{2}\left(\omega_{m}, \omega_{n}\right)$. The unit for $u_{2}$ is $1 / \mathrm{m}$, and rad $/ \mathrm{s}$ for the wave frequency.

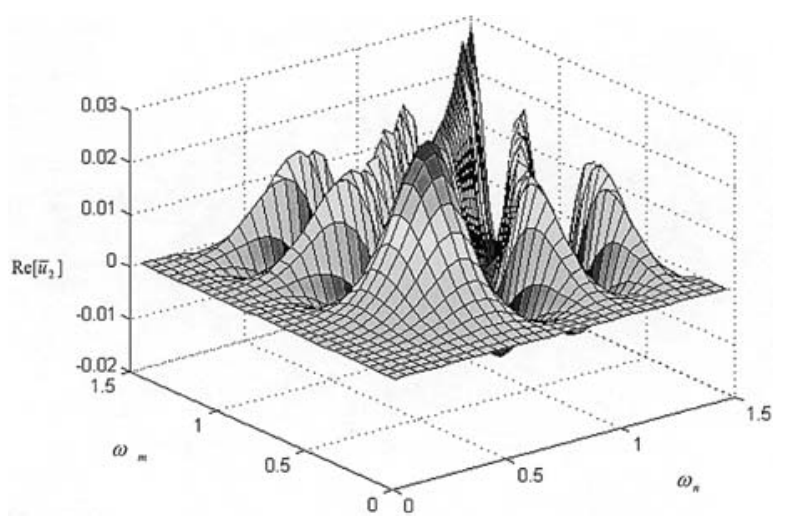

Fig. 9. Real part of $\bar{u}_{2}\left(\omega_{m}, \omega_{n}\right)$. The unit for $\bar{u}_{2}$ is $1 / \mathrm{m}$, and $\mathrm{rad} / \mathrm{s}$ for the wave frequency.

second order GM-variation is strongly related to the first order one, i.e. high second order GM-variation is associated with the high first order one.

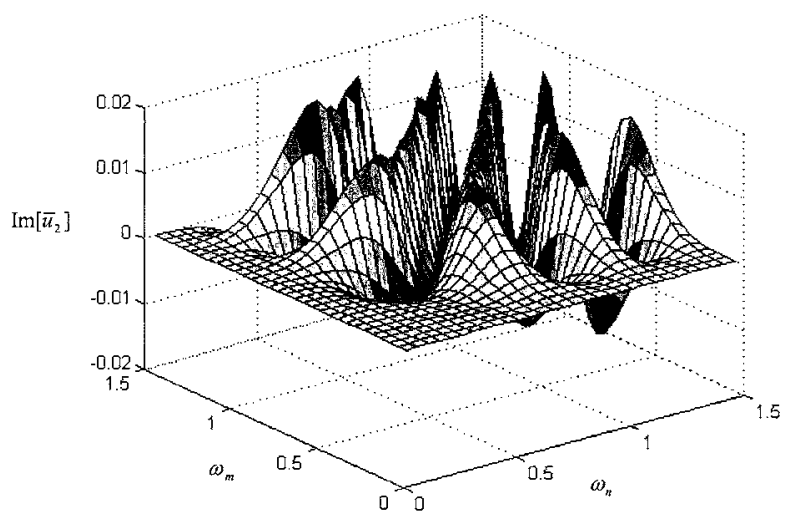

Fig. 10. Imaginary part of $\bar{u}_{2}\left(\omega_{m}, \omega_{n}\right)$. The unit for $\bar{u}_{2}$ is $1 / \mathrm{m}$, and rad/s for the wave frequency.

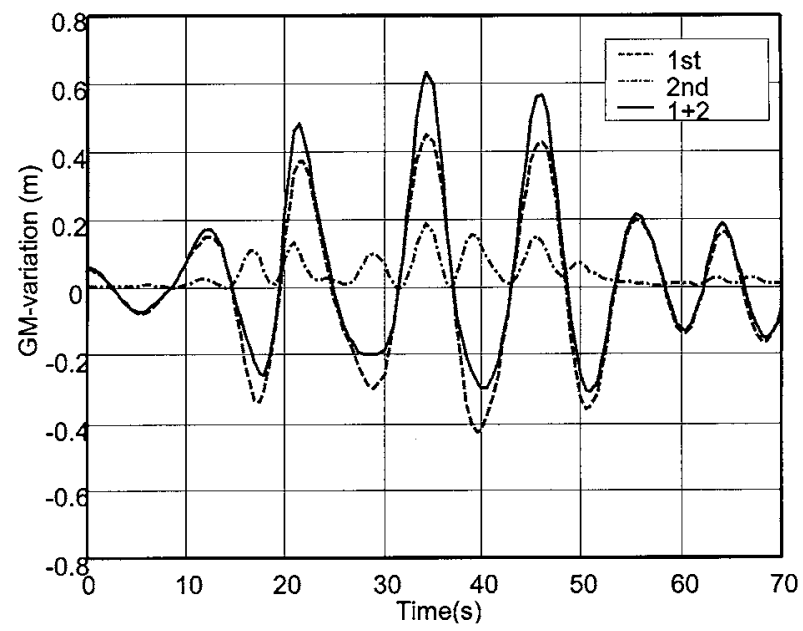

Fig. 11. First and second order GM-variation in an irregular wave with Hs $=2$.

\section{CONCLUSION}

The most significance of the derived Volterra system representation is that the effect of hull geometry on the GM-variation is explicitly expressed in a function series $G_{i}(x)$ which are characteristic functions for the different order GM-variations. Eq. (17) and Fig. 2 show clearly that the first order GM-variation is governed by the product of the hull side slope times the water line beam in quadratic and the relative motion along the ship, and that the second order one by the product of the hull side curvature times the water line beam in quadratic and the relative motion in quadratic along the ship. Hence, it becomes apparently why RoRo-ship have considerably GM-variation in waves due to its large breadth to draft ratio and large flares at fore and aft bodies.

The Volterra system approach is a mathematical 
theory for treatment of nonlinear electronic and mechanic problems. By the Volterra system representation, one has the possibility to analyze a problem in a mathematical sense, such as to determine the characteristics of the problem, to derive the correlation between the input parameters and output results, and the probabilistic nature of the results due to a stochastic input. For an example, by applying the second order probability theory formulated by Naess [6] it becomes possible to calculate the peak value distribution of the GM-variation of a ship in irregular waves. Monte-Carlo simulation technique is a practical approach for similar problems.

As shown by the numerical results, the Taylor's series has been successfully used for the representation of the hull form in the vicinity of the draft line, and thereby provides the basis for the Volterra system representation of the GM-variation of a ship in following or heading waves. This technique should be extended for the description of the coupled sway, heave, pitch and yaw motion of a ship in following and quartering waves. It is of fundamental interest for the study of dynamic instability problems such as broaching-off, course instability coupled with the stability loss in quartering wave, etc. These problems can then be analyzed taking the higher order effect into account by means of the Volterra system theory. Further extension work shall be done in another paper.

\section{REFERENCES}

1. Dunwoody, A.B., "Roll of a Ship in Aster Seas - Response to GM fluctuations," Journal of Ship Research, Vol. 33. No. 4, pp. 284-290, (1989).

2. Hua, J., "A Study of the Parametrically Excited Roll Motion of a RoRo-Ship in Following and Heading Waves," International Shipbuilding Progress, Vol. 39, No. 420, pp. 345-366, (1992).

3. Hua, J. and Rutgersson, O., "A Study of the Dynamic Stability of a RoRo-Ship in Waves," STAB'94, Florida,
(1994).

4. Palmquist, M., "On the Statistical Properties of the Metacentric Height of ships in Following Irregular Seas," STAB'94, Florida, (1994).

5. Rugh, W.J., "Nonlinear System Theory - The Volterra/ Wiener Approach,” The John Hopkins University Press, Baltimore and London, (1981).

6. Naess, A., "Statistical Analysis of Second-Order Response of Marine Structures," Journal of Ship Research, Vol. 29, No. 4, pp. 270-284, (1985).

\section{利用伏特娜系統描述船舶在波浪中 之定傾高變化 \\ 華建波}

瑞典皇家工學院載具工程系

王偉 輝張建仁

國立台灣海洋大學系統工程暨造船學系

摘 要

一艘船的定傾高 $(\mathrm{GM})$ 在非規則波中的變化並非 是純線性的過程, 此項非線性特性尤以非常規型船最 爲顯著。本文將GM的變化推導成一組函數級數, 因 而可用伏特娜(Volterra)系統來表示。將船體剖面線 型寬度、剖面積及剖面積慣性矩因瞬時水線的變化, 而用泰勒(Taylor)级數描述。因此不同階數的變化函 數可利用數值積分求得。如此, 船體線型與 GM的變 化可用顯函數直觀表示。由實例計算結果顯示, 伏特 娜系統中的二階項對 GM在波浪中的變化有明顯的影 響。顯然, GM在非規則波中的變化, 其非線性特徵 可以輕易利用既有的非線性機率理論與蒙地卡羅 (Monte-Carlo) 模擬技術來進行分析。 